\section{REFLEXIONES SOBRE EL MIEDO EN EL SIGLO XXI: FILOSOFÍA, POLÍTICA, GENÉTICA Y EVOLUCIÓN}

\author{
Francesc Mestres \\ Universitat de Barcelona \\ fmestres@ub.edu \\ José Vives-Rego \\ Universitat de Barcelona \\ jvives@ub.edu
}

Cómo citar este artículo/Citation: Mestres, F. y Vives-Rego, J. (2014). "Reflexiones sobre el miedo en el siglo XXI: filosofía, política, genética y evolución". Arbor, 190 (769): a172. doi: http://dx.doi.org/10.3989/arbor.2014.769n5011

Recibido: 17 junio 2013. Aceptado: 20 marzo 2014.

RESUMEN: La actualidad y los acontecimientos de las últimas décadas han puesto de manifiesto la importancia del miedo en la vida pública. El miedo como tal y sus factores desencadenantes están presentes en la prensa, el discurso político, la neurociencia, la ciencia y la filosofía política. Entendemos que la gestión del miedo intuitivo, cognitivo y heurístico debe contemplarse como un elemento básico en la vida del ciudadano de este siglo. Tanto en la visión moderna de la nación y el contrato social, como en las visiones más futuristas de cosmopolitismo y estados supranacionales, la heurística del miedo difícilmente podrá desaparecer de los sistemas jurídicos y sociales, no solo por su utilidad intrínseca, sino también por su inmanencia y consubstancialidad genéticobiológica y psico-social. El hecho de que exista miedo consideramos que es positivo puesto que nos alerta de riesgos que pueden afectar negativamente el futuro del individuo.

PALABRAS CLAVE: Miedo; genética; evolución; heurística; hermenéutica.

\section{REFLECTIONS ON FEAR IN THE 21ST CENTURY: PHILOSOPHY, POLITICS, GENETICS AND EVOLUTION}

Copyright: (C) 2014 CSIC. Este es un artículo de acceso abierto distribuido bajo los términos de la licencia Creative Commons Attribution-Non Commercial (by-nc) Spain 3.0.

ABSTRACT: Recent events and those of past decades highlight the role of fear in public life. The fear and its causes are present in the mass media, political discourse, neuroscience, science and political philosophy. We take the view that intuitive, cognitive and heuristic fear management needs to be considered a basic feature of citizens' lives in the current century. In both the modern vision of the nation and in the social contract, as well as in the most futuristic visions of cosmopolitanism and supranational states, the heuristic of fear will not disappear, not just because its intrinsic utility, but also its immanence at the genetic-biological and psychosocial level. We believe that the existence of fear is positive, as it alerts us to risks that may have a negative impact on the individual's future.

KEYWORDS: Fear; genetics; evolution; heuristic; hermeneutics. 


\section{PREÁMBULO CONCEPTUAL Y TERMINOLÓGICO}

El miedo es un elemento esencial en nuestras vidas, que debería examinarse y estudiarse con más atención en sociología y filosofía. Todos hemos experimentado miedo en alguna ocasión y todos usamos una variedad de términos relacionados con él y que designan distintos grados de la misma emoción: temor, espanto, pánico, terror, etc. En este trabajo, nos referimos al miedo como una emoción ${ }^{1}$ pero en el sentido más neutral de la palabra y siempre entendido como respuesta a un estímulo, es decir tenemos miedo de algo. De entre las muchas maneras que hay de aproximarse al miedo desde la literatura, psicología, etología, neurociencia, sociología y filosofía, en este trabajo vamos a centrarnos en el miedo desde la perspectiva proposicional, es decir desde las creencias, deseos y sobre todo desde las actitudes evaluativas. Un ejemplo de miedo proposicional sería: el sujeto $A$ tiene miedo de $\mathrm{P}$ (que le asalten en la calle, quemarse, perder el trabajo, tener dolor, etc. $)^{2}$. En cualquier caso, el miedo según R. Gordon (1987) y O. Hansberg (1996) siempre tiene un efecto motivacional (tanto si es temerario, paralizante o inteligente siguiendo la clasificación genética del miedo que desarrollamos en este artículo).

El miedo es una respuesta biológica innata que ha tenido una función básica en la perpetuación de las especies. Es una respuesta perturbadora, afectiva (compuesta de sentimientos y/o emociones), automática, normalmente de duración reducida y difícilmente evitable. En el ser humano se localiza en la amígdala cerebral aunque también está regulado por el córtex frontal. Es un fenómeno común a todos los animales y su expresión produce reacciones secundarias de tipo vegetativo como el sudor frío, taquicardias, hipoxia, dificultades para hablar, etc. Biológicamente se considera un mecanismo de supervivencia, útil y beneficioso ya que permite antecederse y reaccionar ante los peligros del mundo en que estamos inmersos y que debemos afrontar. El miedo tiene una base genética transmisible que apareció y evolucionó en nuestros antecesores biológicos, pero también se desarrolla en los individuos a través de un proceso de aprendizaje que es específico de cada persona. Con mucha frecuencia el miedo tiene su base en lo desconocido y por tanto el conocer y entender su origen minimiza o incluso puede evitar su expresión.

El miedo nos aproxima a la realidad por medio de una intuición y a partir de ese momento es conocimiento y representa un lenguaje universal. Los términos relacionados con el miedo, pánico y terror tienen una causa y origen en unos estímulos que son objetivables y definibles y se generan ante un hecho u objeto definido. En consecuencia, entendemos por heurística del miedo, la capacidad de los humanos para pensar y ejecutar innovaciones positivas para sus propios fines a partir de la emoción del miedo. Desde la filosofía, entenderíamos por hermenéutica del miedo a la técnica tradicional de interpretar utilizada para descubrir significados ocultos. Es decir, para poder explicar e interpretar la experiencia del miedo, es necesario asumir que se trata de una emoción presente tanto a nivel individual como social, que además puede gestionarse de manera útil tanto biológicamente (como animales que somos) como desde la perspectiva vivencial humana. El miedo en definitiva es el reconocimiento de nuestra vulnerabilidad y por tanto conlleva valores como la protección, la prudencia, la ayuda mutua, el evitar daños trascendentales, etc. Partiendo de que en determinadas circunstancias el miedo es una herramienta de opresión y alienación, no debemos olvidar que su adecuada gestión constituye un elemento necesario y útil a la sociedad y al ciudadano de hoy y del próximo futuro. Entendemos por tanto que la hermenéutica y la heurística del miedo deben ser un camino irrenunciable tanto en la educación como en el comportamiento del ciudadano y del político.

El valor del miedo no reside tanto en la respuesta emocional como en lo que representa el entender y gestionar sus causas y sus posibles consecuencias. En este sentido la gestión es un proceso valorativo tanto de los elementos desencadenantes (estímulos) de la respuesta emocional del miedo como su gestión en relación a los objetos proposicionales (aspecto teleológico). La gestión más o menos inteligente del miedo puede tener consecuencias positivas tanto desde una perspectiva individual como evolutiva, dado que nos conduce a dos situaciones: i) detectar situaciones peligrosas y ii) desencadenar los procesos valorativos de esos peligros que permitan tomar o intentar tomar decisiones con anticipación. Esa mejor o peor gestión del miedo está supeditada a la educación emocional a la que el individuo ha sido sometido. Es por ello que el miedo surge con mayor presencia y potencia ante la ausencia de la educación, los principios éticos y morales e instituciones y leyes justas y democráticas (Sklahr, 1989).

Del mismo modo que el sismógrafo nos detecta y cuantifica la intensidad del terremoto, el miedo nos sirve de detector e incluso de cuantificador de los 
peligros que nos acechan. Utilizando el mismo símil, al igual que si desconectamos el sismógrafo el terremoto no detiene su actividad, las pretendidas desconexiones o supresiones o evitaciones del miedo no eliminan los peligros potenciales que desencadenan el miedo. Cuanto más sensible y preciso sea nuestro sismógrafo del miedo, mejores serán nuestras posibilidades de anticiparnos a los peligros y poder generan respuestas eficientes e inteligentes frente a él.

En este trabajo solo trataremos las expresiones emocionales del miedo que pueden ser objeto de gestión inteligente o racional. Excluimos de la categoría de miedo inteligente a sus manifestaciones que por su naturaleza impiden los actos reflexivos y los juicios de valor que favorecen las decisiones inteligentes, por ejemplo el pánico o miedo paralizante a nivel físico y mental o el otro extremo constituido por la insensatez temeraria o suicida que tarde o temprano llega a dañar o destruir a la persona.

\section{EL MIEDO EN EL MUNDO CONTEMPORÁNEO}

La realidad histórica y la experiencia de los últimos siglos, han demostrado que el loable objetivo de una convivencia pacífica entre todos los estados ${ }^{3}$ está muy lejos de cumplirse. El proyecto de paz perpetua desde sus diferentes formulaciones ha sido desplazado en la dirección de las premisas del estado de naturaleza y del miedo al otro y a la muerte violenta que Hobbes propuso en su Leviathan (1651). Los últimos siglos se han caracterizado por una permanente situación de guerra convencional entre los estados, cuando no de guerrillas intra o inter estatales. En las últimas décadas se ha encumbrado el modelo de disuasión, que no es más que el miedo a los ejércitos más poderosos llegando a la máxima expresión hobbesiana en las denominadas intervenciones militares preventivas y las guerras justas ${ }^{4}$.

Tradicionalmente el poder (social y político) se caracteriza por su dual utilización del miedo. Por un lado el poder da miedo a todos aquellos que no le secundan y por tanto favorece su instauración y perduración. Pero por otro lado, el poder se afianza en una sociedad y en los individuos si ese poder les protege de sus miedos, por ejemplo, si los ciudadanos o la sociedad se sienten protegidos de la delincuencia, las penurias y desastres, los enemigos o invasores, etc.

En su obra El miedo a la libertad Erich Fromm (recomendamos la reedición de 2005), describe como el hombre ha ido adquiriendo más y más libertad, alejándose progresivamente de la represión a la que estaba sometido. Este factum, le genera un sentimiento de desarraigo y soledad, dado que anteriormente, tenía fijado un patrón de conducta basado en el sometimiento y al perderlo se siente desorientado. Esta situación, produce en el hombre un ansia o necesidad de sentirse unido a algo, lo que en ciertos casos explicaría su adhesión a la religión o los regímenes totalitarios, es decir el someterse de nuevo a una fuerza que él cree superior, algo que le pueda garantizar una seguridad y confianza que siendo libre no poseía. La crisis de libertad se puede observar claramente en todos los regímenes autoritarios, como los fascismos, especialmente el nazismo, el cual estudia Fromm mostrando la psicología tanto de su líder como de sus partidarios, y lo que les estimuló a obrar de ese modo. De la misma manera Fromm analiza los inconvenientes que crea la libertad en el hombre moderno, tratando el tema de la estandarización de los individuos y los patrones preestablecidos de comportamiento a los que lleva la democracia actual. Dicho de otra manera, el hombre actual tampoco es libre porque las ideologías preestablecidas lo obligan a perder su identidad personal, y su yo se ve diluido o hundido, ya que muestra lo que la sociedad le estipula. Finalmente, llega a la conclusión de que tras un proceso de evolución, el hombre teme a la libertad ya que al poseerla se siente desarraigado y necesita estar atado a algo. En resumen, Fromm nos ha presentado al hombre a lo largo de la historia, en la que poco a poco ha ido ganando en libertad pero también ha ido asiéndose a fuerzas mayores en las que se refugiaba, creando un hombre moderno que en esencia es libre, pero que se ve obligado por la educación y la sociedad a adquirir el pensamiento único, creando individuos autómatas e iguales.

Joanna Bourke en su obra El miedo: una historia cultural (reedición de 2005), afirma que ahora somos más miedosos que en el siglo XIX. Seguramente, los miedos posibles cuantitativamente hablando, han sido más o menos los mismos a lo largo de la Historia, pero la sociedad de la información nos ha acercado más a ellos. Por otro lado, muchos miedos se han globalizado: el terrorismo, el crimen organizado, las epidemias, el cambio climático, por no mencionar la crisis económica actual son claros ejemplos que hacen que posiblemente tengamos motivos para ser más miedosos que en siglos precedentes. Antes solo se estaba en contacto con los miedos más inmediatos y obvios, en cambio ahora tenemos que confrontarnos con todos los miedos posibles del mundo. En la 
sociedad moderna actual ya no son tan prominentes los miedos ancestrales a la Naturaleza, al hambre, las guerras, la enfermedad y la muerte. Salvo situaciones ocasionales (accidentes nucleares, terremotos, inundaciones, grandes incendios, etc.), los miedos de antaño se han sustituido por otros miedos (¿quizás menores?) como el miedo a ser robado o violado, a perder el trabajo, la casa o el patrimonio o miedos más abstractos como la crisis, ser desgraciado, no tener un cuerpo atractivo, o no triunfar. De hecho nuestras vidas también pueden estar conectadas al miedo a través de las personas que nos rodean, por ejemplo el miedo a nuestros jefes o superiores, o incluso el miedo entre padres e hijos o entre consortes, familiares o conocidos. En la segunda mitad del siglo $\mathrm{XX}$, han surgido tipos nuevos de miedos como son los casos de miedo al holocausto nuclear, al desastre ecológico o a sí seremos capaces de trasmitir a las generaciones futuras un futuro sostenible y en caso de alcanzarlo, si será a través de un sistema dictatorial hobbesiano o marxista o bien a través de un sistema cosmopolita y democrático. Han sido precisamente este tipo de temores ecológicos los que han dado lugar al surgimiento de la denominada ciudadanía ecológica o ciudadano ecológico ${ }^{5}$.

Uno de los exponentes actuales en filosofía política, D. Gauthier, nos da una nueva visión del Leviathan de Hobbes en su trabajo The Logic of Leviathan (1969) en el que realza a Hobbes como teórico político y como teórico moral a través de su neocontractualismo hobbesiano. Según Gauthier, los conceptos de "obligación" y "autorización" de Hobbes son fundamentales a la hora de interpretar las relaciones entre soberano y sujeto o en su versión actual entre gobierno y ciudadano. La nueva lectura del Leviathan (es decir, del miedo al poder absolutista como forma de gobierno) que nos propone Gauthier es que la justificación y el mantenimiento de las estructuras políticas y legales (es decir, la democracia) se sustenta en una constitución democrática que expresa y representa la voluntad del pueblo a través de una solución contractualista. Esta valoración e interés en Hobbes es lo que separa a Gauthier de otros contractualismos contemporáneos, pero en cualquier caso es una reintroducción de Hobbes en la tradición contractualista y liberal.

En una línea similar, los pensadores Lacleau y Mouffe (1985) y Mouffe (1993 y 2000) mantienen una posición hobbesiana democrática, es decir, que democráticamente decidimos un poder coactivo y asumimos que el miedo al otro y a la violencia ex- terna nos fuerza a comportarnos cumpliendo la Ley básicamente por temor al castigo que supone transgredirla. En tales circunstancias el miedo hobbesiano pasaría de ser un miedo al otro a tener miedo al grupo o sociedad como elemento coactivo. A pesar de que sigue habiendo pensadores que creen que puede haber un orden no autoritario (Leclau y Mouffe entre ellos), ni se observan evidencias de que tal situación se dé en las sociedades avanzadas ni pensamos que tales procederes puedan ser más eficaces que los basados en el miedo biológico ancestral, todavía existente en las bases neurológicas de los humanos y por supuesto de todos los animales.

Finalmente Daniel Innerarity y Javier Solana en su reciente libro La humanidad amenazada: gobernar los riesgos globales(2011) y especialmente en el capítulo 8, plantean que tenemos que aprender a tener miedo de nuevo, aunque ese nuevo miedo se exprese de manera diferente al hobbesiano a pesar de tener las mismas raíces biológicas, sociales y en el límite filosóficas.

El pensamiento político liberal contemporáneo manifiesta un claro desplazamiento hacia el modelo hobbesiano, basado en el miedo al poder político, jurídico y policial. Esta deriva o desplazamiento no llega a los extremos que en su momento alcanzaron el estalinismo, el maoísmo y las numerosas dictaduras del área mediterránea, Europa del este, Asia y América. Sin embargo, parece indudable que al menos ciertos sectores no minoritarios de la social liberal contemporánea plantean que la contrapartida que ofrece el liberalismo es volver al contrato social basado en el autoritarismo y el miedo. En definitiva, el miedo al otro, subsiste bajo concreciones vinculadas a creencias políticas (comunismo, dictaduras, imperialismo) y religiosas (islamismo y otros fundamentalismos).

Puede advertirse, que inherente a la apelación del miedo y el discurso del terrorismo como operador político del poder, subyace una heurística del miedo como recurso político de dominación, control y sometimiento. La referencia al terrorismo no está desvinculada de las necesidades de la geopolítica y esta de las necesidades de control político y militar ${ }^{6}$. De la misma manera que la administración de G. Bush (hijo) utilizó en su política interna y externa el terrorismo como argumento de disuasión y generó una serie de alertas que mantuvieron a la sociedad norteamericana en vilo, asustada y en permanente tensión, ahora se utiliza el recurso del miedo como operador más general de la geopolítica en la lucha contra el terrorismo. 
Electoralmente hablando el voto del miedo es cada vez más frecuente en las elecciones de todos los países modernos. Las diferentes formaciones políticas evocan al miedo a la violencia callejera, a la inmigración, a perder el puesto de trabajo o a las prestaciones sanitarias o educativas. El absolutismo propugnado por Maquiavelo, Bodin y Hobbes fue y sigue siendo en la actualidad una pretensión funcional, puesto que para llegar a él, el monarca, estado o sociedad debe pactar con los poderes locales, territoriales y los diferentes estamentos sociales. No puede existir dictadura sin esos pactos. La complejidad de ese pacto absolutista-dictatorial es mayor cuando más complejas son las estructuras sociales (sindicatos y patronales, grupos profesionales, empresas, instituciones públicas, entidades internacionales, etc.). Hoy día la emergencia de los poderes financieros internacionales, externos e independientes del Estado, hacen más difícil que nunca alcanzar a ese poder absoluto o dictatorial de corte hobbesiano. Para Locke el poder nace del consenso y actualmente cabe hablar del contrato social, pero en cualquier caso esa autoridad de la que nos queremos defender pero al mismo tiempo necesitamos, solo es eficaz en la medida que infunda miedo a los que no cumplan con sus dictados.

\section{TRASCENDENCIA BIOLÓGICA DEL MIEDO}

Consideramos pertinente subrayar que la biología ha verificado que todos los animales (hombre incluido) son hobbesianos y que el miedo al daño o castigo genera unas respuestas de huida, lucha o sumisión que son universales en los seres vivos. La cadena trófica piramidal se sustenta en las interacciones presa - predador - omnívoro y en tales circunstancias la huida y el miedo son elementos imprescindibles para sobrevivir. Biológicamente hablando, un animal sin miedo a sus enemigos e incluso a las fuerzas de la naturaleza (fuego, agua, frío, calor, etc.) no tiene la menor posibilidad de sobrevivir a corto plazo. El miedo, de manera especial en los humanos desempeña un papel crucial, puesto que nos alerta de los peligros que nos acechan, de modo que podamos anticiparnos en reacciones de huida, defensa o combate. El miedo es un conjunto de sensaciones que se ponen en marcha ante situaciones que suponen una amenaza para nosotros. La reacción de miedo ha sido clave para la supervivencia de los humanos a lo largo de la historia y continua siéndolo. Sentir miedo cuando vemos como un tigre hambriento corre hacia nosotros es adaptativo, nos hace correr y tratar de ponernos a salvo. Si no existiera la reacción de miedo, probablemente la especie humana habría desaparecido hace tiempo.

Pero, ¿en qué consiste biológicamente la reacción de miedo? Cuando vemos un peligro real que supone una amenaza para nosotros se pone en marcha un mecanismo que prepara al organismo para hacer frente a la situación, es decir, se producen un gran número de cambios corporales que "nos preparan para la acción" como son el aumento de la tasa cardiaca, la respiración, sudoración, contracciones estomacales, etc. Esta reacción pone a nuestra disposición todos los recursos energéticos disponibles para afrontar la situación, escapando o afrontándola. La amígdala es la sede neuroanatómica principal del miedo y es el núcleo de las decisiones y el autocontrol. Detecta y organiza las respuestas a los peligros naturales (como los depredadores) y aprende respecto a nuevas amenazas y estímulos que predicen dichos sucesos (LeDoux, 1998). La amígdala consta de 13 núcleos y estructuras corticales, se localiza en el circuito límbico y está conectada al córtex prefrontal. Si no hay conexión o ésta es hipofuncional, es cuando aparece el miedo paralizante patológico, pero si la conexión funciona de modo adecuado, se manifiesta lo que denominamos el miedo "positivo". El miedo constituye una respuesta emocional compleja que anticipa un estímulo evasivo. Es una reacción normal (positiva) ante situaciones amenazantes y es corriente en la vida diaria. Se producen patologías respecto al miedo o la ansiedad cuando un miedo sobrepasa un cierto nivel o tiene una causa inapropiada (Nesse, 1990; LeDoux, 1998). Aunque el miedo no se borra ni desaparece en el individuo que lo vive, se puede reeducar y se puede gestionar de manera positiva.

\section{LA GENÉTICA Y LA EVOLUCIÓN BIOLÓGICA DEL MIEDO}

Entendemos por evolución biológica los cambios de los seres vivos en el tiempo, y por tanto también es aplicable al ser humano. Solamente aquellos cambios en los caracteres que sean hereditarios podrán ser utilizados por la evolución. En consecuencia se ha de definir de la forma más precisa posible el carácter en el sentido genético del término y posteriormente estudiar si tiene una base genética o no. En primer lugar hay que indicar que es difícil definir el carácter genético del miedo. De hecho existen diferentes subtipos de miedo, y por ejemplo, la gente que tiene una fobia social puede estar aterrada de ser el centro de atención, pero en cambio no sentir miedo 
frente a las serpientes (Nesse, 1990). El miedo entra en la categoría genética de los caracteres complejos, es decir, estaría controlado por factores genéticos y también por efectos ambientales (Benito y Espino, 2012). Analizando dicho carácter, Hettema y Kendler (2003) intentaron estimar la fracción genética responsable de su control. A partir de estudios con hermanos gemelos monocigóticos (también denominados "idénticos" pues provienen de una única fecundación lo que implica que son genéticamente iguales) y dicigóticos (también llamados "hermanos" al provenir de dos fecundaciones independientes y ser genéticamente como dos hermanos cualquiera) dedujeron que el miedo presentaba una heredabilidad entre el $35 \%$ y el $45 \%$. La heredabilidad es una estima que, respecto a la variación total de un carácter en una población, nos indica que fracción de dicho carácter es atribuible a factores hereditarios y cual a ambientales ${ }^{7}$. Si esta heredabilidad es del $100 \%$ indica que el carácter está únicamente controlado genéticamente y los factores ambientales no tienen ningún efecto sobre él. En cambio, un valor del $0 \%$ se interpretaría justamente al revés, el componente genético sería nulo y el carácter dependería solo de factores ambientales. Por tanto, según estos autores el componente genético del carácter miedo tendría un cierto efecto pero no sería el mayoritario, mientras que los factores ambientales tendrían un papel más importante. Este estudio tiene una serie de limitaciones, como los mismos autores destacan, pero es una aproximación a tener en cuenta. Puede trazarse el origen de algunos de los componentes del miedo hasta la base de la línea evolutiva de los mamíferos, otros hasta el de los simios y algunos en la propia línea evolutiva del hombre (Homo sapiens). Por ejemplo, según Bracha et al. (2005) algunos genes responsables del miedo vendrían del Neolítico. Como era de suponer, cada uno de estos componentes del miedo tiene diferentes valores para su heredabilidad (Bracha, 2006), y por tanto cada uno de ellos dependerá en su manifestación fenotípica de diferentes combinaciones de factores genéticos y ambientales. Se han propuesto algunos modelos genéticos y algunos genes candidatos (genes que se supone que pueden tener un efecto sobre el carácter estudiado). Estos genes pueden buscarse a partir de algunas patologías del miedo mediante técnicas de genética molecular humana, tales como el ligamiento, la asociación, la genómica comparada y otras. Otra forma de entender la fisiología del miedo y de buscar genes candidatos es mediante el estudio de las alteraciones en el comportamiento causadas por daños en la estructura cerebral. Por ejemplo, ciertos daños en la amígdala ocasionan que los monos pierdan su miedo a las serpientes o que las ratas lo pierdan respecto a los gatos (LeDoux, 1998).

Como ya hemos comentado, el miedo normal (positivo), es un mecanismo de defensa ancestral en los animales. La selección natural ha modulado el miedo y las reacciones asociadas para sobrevivir (Nesse, 1990). Desde una perspectiva evolutiva, el miedo origina una serie de comportamientos defensivos que ayudan a los organismos a enfrentarse a diversos tipos de amenazas que afectan a su supervivencia (Bolles, 1970; Blanchard and Blanchard, 1988; Panksepp, 1998). Como es un sistema de relevancia inmediata que afecta a la supervivencia, se considera que ha sido de una importancia crucial en la evolución de los mamíferos (Mineka y Öhman, 2002). En general, el miedo induce a los animales a escapar o a evitar las situaciones de peligro. La evolución biológica ha hecho de algunos objetos o situaciones fuentes innatas de miedo (Russell, 1979) y ha moldeado algunas respuestas automáticas de huida. Sin embargo todos los mamíferos son también capaces de aprender a tener miedo a partir de objetos inicialmente neutros o de situaciones que han demostrado ser una amenaza o un peligro a través de un condicionamiento de tipo pavloviano (Mineka, 1979). Por tanto, se puede pensar que a lo largo del proceso evolutivo posiblemente la selección natural ha moldeado el miedo y el aprendizaje del miedo. Los miedos y las fobias no tienden a ocurrir en un grupo arbitrario de objetos o situaciones asociadas con traumas (accidentes) y en vez de ello están más probablemente asociadas a tener lugar respecto a objetos y situaciones que eran peligrosos en épocas del hombre pre-tecnológico (Mineka y Öhman, 2002).

Desde una perspectiva antropológica evolutiva, se considera que el miedo en los humanos ha pasado por diferentes etapas acumulativas, como ya hemos comentado previamente en los casos en que se puede trazar el origen evolutivo de algunos componentes del miedo. Por ejemplo, el miedo a las alturas está presente en todos los mamíferos y posiblemente se desarrolló en el mesozoico (Bracha et al., 2005; Bracha, 2006). En cambio el miedo a las serpientes se pudo desarrollar en los simios durante el cenozoico (Bracha et al., 2005; Bracha, 2006) y actualmente sabemos que estos animales reaccionan de manera muy rápida ante la visión de las serpientes, gracias a unas neuronas de la zona pulvinarmedial y dorsolateral (Van Le et al., 2013). El miedo a los 
insectos o a las ratas posiblemente sea más tardío y debió desarrollarse durante el paleolítico y el neolítico cuando transmitían enfermedades y destrozaban las cosechas y los alimentos guardados celosamente en las cavernas (Bracha, 2006). Por tanto el miedo es también un juicio, pues a través del miedo valoramos de forma extremadamente rápida una situación y detectamos que hay un peligro, algo malo para nosotros. Acto seguido, y también de forma muy veloz, "enjuiciamos" que debemos hacer: huir, defendernos, atacar, etc. Puede ser que acertemos o no con nuestra decisión y de ello dependerá el salir indemne o sufrir un daño. Si el ser humano sobrevive, guarda en su memoria la experiencia y le puede ser útil para el futuro. Esta experiencia la puede transmitir a sus congéneres, con lo que ellos también podrán afrontar mejor una futura situación similar (Olsson y Phelps, 2007). Es decir, habrá una evolución no genética (evolución cultural y por tanto horizontal), que se basará en las experiencias, aprendizajes y la transmisión de la información sobre situaciones peligrosas y como evitarlas o superarlas. Tanto la evolución biológica (mediante la selección natural) como la cultural (transmisión de las experiencias) han permitido llegar hasta el hombre moderno.

En el ser humano podemos describir diferentes niveles de miedo, que siguen una distribución en la que la zona central correspondería a valores normales (positivos) de miedo. Hacia uno u otro de los extremos tendríamos situaciones no normales. Los miedos excesivos del sujeto autoreflexivo, son los que básicamente conducen a situaciones psico-patológicas, por ejemplo al pánico, o situaciones paralizantes, etc. En cambio, hacia el otro extremo tendríamos a las personas temerarias o inconscientes ante diversas formas de peligro. La selección natural tenderá a favorecer a los individuos de la zona central de la distribución y a eliminar a los de ambos extremos por no ser biológicamente tan eficaces. Un individuo agarrotado de miedo no será capaz de sobrevivir en su entorno y uno que sea temerario sucumbirá ante una situación de peligro que no ha sido convenientemente valorada. Si la selección natural actúa sobre el carácter miedo, ¿por qué siguen apareciendo personas con miedos patológicos o extremadamente temerarios? Al tratarse de un carácter complejo, seguramente existirán muchos genes involucrados. Según como se acumulen en una persona nos darán cualquier de los niveles del miedo que hemos descrito: temerarios, normales (positivos) y miedosos patológicos. Muchas enfermedades mentales se comportan genéticamente de la mis- ma manera, aunque la patología se muestre en un solo extremo, como por ejemplo en la esquizofrenia (Strachan y Read, 2010).

El control genético y ambiental del carácter miedo en el ser humano lo podemos poner de manifiesto si nos fijamos en el cambio para dicho carácter a lo largo de nuestras vidas. Por ejemplo, los bebés tienen miedo innato ante rostros desconocidos. Sin embargo, van aprendiendo de sus padres a reconocer el peligro que representa el fuego, los enchufes eléctricos, etc. Los padres y educadores les transmiten la sensación de miedo ante estos peligros. Por tanto, hay un periodo cultural de aprendizaje de las situaciones del miedo. Este aprendizaje comporta también saber cómo gestionar el miedo. Este es una señal de aviso ante un peligro y es necesario responder adecuadamente ante la situación difícil. Aprender a gestionar de modo flexible el miedo, actuar racionalmente ante él, etc. implica un proceso de aprendizaje. Al llegar a la vejez se invierte el proceso, perdiéndose la sensación de miedo y conduciendo a las personas mayores a realizar imprudencias.

Hay muchas situaciones que dan miedo, que despiertan miedo o que sugieren miedo, por ejemplo imágenes que activan en el cerebro del que las ve las sensaciones de miedo, angustia o terror, como por ejemplo lo extraño, lo oscuro, lo incierto, lo deforme, lo desproporcionado, lo que no tiene vida pero se mueve o actúa y no debemos olvidar el miedo a lo desconocido y también a la libertad. Sin embargo, ninguna imagen puede explicar el miedo, únicamente lo puede evocar, si tenemos previamente algún miedo relacionado con esa imagen, lo que indica que el miedo es un proceso mental vinculado a la memoria y a cierto tipo de información.

Desde hace siglos nos preguntamos ¿por qué tenemos las capacidades para amar, odiar, temer o ser felices o estar tristes? ¿Qué función biológica tienen? Hasta la fecha no se han encontrado respuestas ni desde el mundo de la ciencia ni desde la filosofía, sin embargo hay un consenso cada vez mayor que supone que cualquier respuesta debe basarse en la aceptación de que ha sido a través de la selección natural lo que ha configurado esas emociones al presentar una ventaja evolutiva. Es decir, las emociones y el miedo, como cualquier carácter que ha sido moldeado a lo largo del proceso evolutivo, se han seleccionado en la mayoría de los casos por haber aportado alguna ventaja a sus portadores. La pregunta que sin embargo todavía no podemos responder es si hoy todavía son úti- 
les a los humanos o no, bajo qué circunstancias y en qué medida. No creemos que haya teleología en las emociones y si un ontología es decir que han sido útiles y todavía pueden serlo. Entendemos que mejorar la adaptación al entorno, básicamente por actuar previniendo y protegiéndonos de peligros y daños (físicos y emocionales), nos permite detectar oportunidades de utilidad en los cambios emocionales y de planning.

\section{COMPRENSIÓN, EDUCACIÓN Y GESTIÓN DEL MIEDO}

La hermenéutica del miedo, representaría la reflexión, comprensión y dilucidación de los diferentes tipos de miedo (temor, ansiedad, terror, etc.) y sus causas. La heurística del miedo sería el proceso reflexivo y educativo por el que asumiríamos el miedo como un elemento necesario para evitar daños y males, teniendo en cuenta que la educación de ese miedo y en ningún caso su supresión a través de procesos culturales o educativos, puede tener ventajas para el individuo. La combinación equilibrada de la heurística y hermenéutica del miedo nos puede llevar a un reaprendizaje para gestionarlo de manera más razonable y eficaz, en por un lado la construcción del nuevo contrato social y su aspectos más políticos y por otro en la actualización del miedo a la Naturaleza y a lo desconocido. El miedo no puede eliminarse puesto que está en la base de la biología y del pensamiento contemporáneo. Sin embargo, sí que se hace necesario transformar y racionalizar su gestión para que pueda resultarnos útil.

Un elemento reciente lo constituyen los miedos a las patologías surgidas en la sociedad occidental de personas como asesinos en serie, secuestradores, torturadores y violadores que enmascarados y a menudo con la coartada de una vida pública o familiar absolutamente normal provocan sorpresa y terror social. Cabe plantearse en qué medida la difusión por parte de la prensa, TV y en particular por las series filmográficas que difunden esos miedos contribuyen a su difusión, implantación o reconfiguración. Si el miedo al otro y a la muerte violenta en la época hobbesiana se centraba en la delincuencia y las guerras, la disminución de esas fuentes de miedo en la actualidad, ha sido sustituida por el temor cuando no miedo al crimen patológico y al terrorismo. Tenemos por tanto motivos para pensar que esas situaciones pueden estar en el origen de respuestas leviathanicas en las sociedades avanzadas de nuestros días.

\section{MIEDO Y SOSTENIBILIDAD}

La muerte violenta causada por las catástrofes naturales puede considerarse como una versión moderna del miedo hobbesiano. El miedo a la Naturaleza, no fue asumido por Hobbes como miedo que pudiese gestar un sistema político leviathanico por entender que poco o nada podía hacer la política y el gobierno civil por impedir los males que infligía la Naturaleza al hombre de entonces. Aunque en la segunda mitad del siglo XX, la sociedad occidental ha reducido sus miedos a la Naturaleza, debido al falso convencimiento de que la tecnociencia puede dominarla, han emergido de nuevo los miedos a la Naturaleza en forma de los efectos que pueden provocar el cambio climático, los huracanes, inundaciones, incendios e incluso los accidentes nucleares que aunque están vinculados a infraestructuras tecnocientíficas, no dejan de sustentarse en los productos radioactivos de la Naturaleza ${ }^{8}$.

El hombre actual, el ciudadano moderno, causa muchos más males y desastres ecológicos que el ser humano de hace uno o dos siglos. Pero ello no es debido a que sea más malo o perverso que aquel, ni que persiga fines menos nobles o más destructivos, es simplemente que el humano actual tiene mucho mayor poder destructivo debido a la enormidad y a la potencia de la tecnología actual que está directa o indirectamente en nuestras manos. Otro elemento que hace mucho más temible a la sociedad actual que a la de hace uno o dos siglos es que ahora somos muchos más y por tanto nuestros actos tienen una potencia multiplicadora mucho más alta que cuando en el planeta había únicamente 2.000 millones de habitantes. Es como comparar los guerreros de las tribus primitivas con un ejército mucho más numeroso y con armamento de destrucción masiva.

Hans Jonas (2004) propone la "heurística del temor" como un mecanismo que pretende anticiparse a las catástrofes ecológicas y al riesgo de desaparición de la humanidad. Conviene destacar que Jonas habla de "heurística" (cálculo) del temor y no de "ética del miedo", como a veces le han reprochado sus críticos. Se trata, básicamente, de hacernos reflexionar sobre el hecho de que somos responsables de la continuidad de la vida en el planeta; pero esa responsabilidad no nos impide actuar, sino que nos invita a hacerlo. Cuando somos conscientes de lo que está en juego (la continuidad de la vida humana) comprendemos también el temor a la destrucción fatal del entorno. Por el hecho de que podemos destruir el planeta, debemos en consecuencia hacernos 
responsables de la posibilidad del mal que podemos infligir y tener miedo por ello. El nuevo reto ecológico no es como mejorar el mundo, si no como conservarlo. Primero debemos parar la destrucción y luego reparar los daños para entonces y solo entonces, mejorar nuestro mundo y manera de vivir 9 .

Ante la destrucción masiva y continuada de la Naturaleza, los recursos naturales y del patrimonio a transmitir a las generaciones futuras, debemos gestionar al miedo de modo que se convierta en un impulsor de la acción, es decir el miedo que nos hace evitar unas cosas y buscar otras. Sin embargo, debe descartarse el miedo como elemento paralizador, puesto que impide la comprensión, ver la realidad y la acción, es decir que impide tomar y aplicar eficazmente las decisiones.

La praxis política actual parece estar realizando la fantasía de Hobbes si bien de forma negativa. Los poderes públicos intervienen de modo cada vez más total en la reglamentación de la vida social. De tal modo que más que un Estado totalitario, lo que tenemos es una sociedad totalitaria. Ello es debido básicamente a que la seguridad (social, económica, institucional, individual, etc.) debe primar sobre las libertades individuales. La fuerza motriz de esta deriva es sin lugar a dudas el miedo hobbesiano a la inseguridad, a perder lo que ya tenemos y que vemos peligrar.

\section{PERSPECTIVAS Y FUTURO DEL MIEDO}

Queremos dejar bien claro, que en ningún momento hemos pretendido ni pretendemos recuperar el miedo como elemento coactivo socio-político. En todo momento nos estamos refiriendo al miedo como una respuesta emocional que nos permite detectar o intuir una situación de peligro para el individuo y precisamente por esa característica consideramos al miedo adecuadamente gestionado, un elemento constructivo y positivo en el ser humano del siglo XXI.

El miedo es un elemento bifronte ${ }^{10}$ que puede manifestarse bajo dos expresiones totalmente contrapuestas. Por un lado el miedo paralizante, que bloquea la actividad de la razón y del cuerpo. Es un miedo que incapacita, aliena y destruye al individuo. Ese tipo de miedo debe gestionarse de modo que se minimice o desaparezca y de paso al miedo intuitivo, captador de información, que nos previene de peligros y daños, que sirve para emitir un juicio sobre que podemos, debemos y tenemos que hacer para proteger al individuo y permitirle sobrevivir ante los peligros del mundo exterior y también de nuestras limitaciones interiores. La gestión del miedo intuitivo, cognitivo y heurístico es la que debe fortalecerse y potenciarse en el ciudadano moderno. Al igual que el dios Jano, el miedo puede augurar un buen final puesto que adecuadamente interpretado (hermenéutica) y educado (heurística) nos puede ayudar a tomar las decisiones que permitan mantener la vida en los cauces de la humanidad avanzada y que progresa.

El miedo preventivo, alertador, potenciador de la intuición, inductor de la reflexión y estimulador de la cooperación y ampliación del entorno puede ser un elemento fundamental en las crisis actuales y las venideras. En contrapartida, debemos eludir al miedo que nos hace recelar del entorno, que nos induce al replegamiento en nosotros mismos cerrándonos a la amplitud de miras y al miedo que nos predispone a ceder cotas de libertad en nosotros y en los demás en aras de una mayor seguridad. En definitiva, el miedo no es una cortapisa para la evolución del individuo, ni una disminución emocional sí va acompañada de la intuición y la capacidad de anticiparnos en la detección de peligros. El verdadero miedo no patológico es una señal al servicio de la intuición, la precaución y la supervivencia, es decir para sobrevivir necesitamos estar protegidos por el miedo. En cambio el pánico o el miedo inmovilizador y también la temeridad son los grandes enemigos de la supervivencia. Tanto en la visión moderna de la nación y el contrato social, como en las visiones más futuristas de cosmopolitismo y estados supranacionales, la heurística del miedo difícilmente podrá desaparecer de los sistemas jurídicos y sociales, no solo por su eficacia intrínseca, sino también por su inmanencia y consubstancialidad biológica. El apelar a la gestión del miedo a nivel político, conlleva implícita la estrategia de reforzar la racionalidad, para poder abrir el debate y las deliberaciones políticas en las que se ha utilizado o en las surge como elemento coactivo.

A lo largo del siglo XX, el conocimiento del miedo desde la perspectiva clínica se ha desarrollado enormemente y se ha traducido en un gran avance en el diagnóstico y tratamientos de las patologías asociadas. También desde la perspectiva social y política se están constatando una serie de preocupaciones relativas al destino de nuestro planeta (cambio climático, merma de recursos básicos, contaminación ambiental, etc.), que pueden ge- 
nerar distintas formas de miedo en la población. El hecho de que exista miedo, tal y como hemos analizado en este trabajo, consideramos que es positivo puesto que nos alerta de riesgos que pueden afectar negativamente el futuro de la humanidad. Por tanto, se hace necesario que la sociedad en su conjunto valore correctamente este tipo de miedos y busque de manera decidida la resolución de sus causas.

\section{AGRADECIMIENTOS}

Agradecemos a Mikel Valverde (Unidad de Agudos de Psiquiatría, Sección A, Servicio Navarro de Salud, Pamplona) su meticulosa revisión de este artículo, así como sus numerosos comentarios, sugerencias y críticas que nos han permitido una mejora substancial del contenido. Nuestro agradecimiento también para Andrea Izquierdo Bouldstridge (Parc Científic de Barcelona, Barcelona) por revisar y corregir el Abstract.

NOTAS

1 Sabemos que en la actualidad hay planteamientos psicológicos y neurológicos que diferencian las emociones de los sentimientos. Sin embargo, en este trabajo los identificamos dado que entendemos que esa diferenciación no es relevante para nuestro análisis.

2 La tesis de que el miedo es implícitamente o explícitamente proposicional ha sido defendida por Gordon (1987), especialmente en los capítulos 2 y 4 . La misma tesis es debatida y mayoritariamente aceptada por Hansberg (1996, pp.31-103)

3 La convivencia pacífica entre los estados fue uno de los objetivos políticos de los tratados de Westfalia de 1648 y el proyecto de paz perpetua fue formulado por Kant en su obra Sobre la paz perpetua de 1795.

4 Danilo Zolo, filósofo italiano, acuñó el término "guerras humanitarias" para indicar un tipo de guerras democráticas a las que nos hemos acostumbrado en el ámbito de la OTAN. Según él las grandes potencias han "suavizado" la noción peyorativa de "agresión" al cambiarla por la de "legítima defensa" tal y como aparece en la Carta de las Naciones Unidas (Artículo 51). "En la mayoría de los casos el concepto de 'agresión' se ha tergiversado y convertido en la idea opuesta de una guerra librada para defender a la humanidad de la amenaza del 'terrorismo global'". Dicho filósofo comenta que la Guerra del Golfo de 1991 y las injerencias en Yugoslavia, Afganistán, Irak, Líbano y Palestina han logrado favorecer el triunfo de la guerra humanitaria por medio de una utilización terrorista, y por tanto del miedo, del poder militar. Siempre según Zolo, la guerra de 1999 contra Yugoslavia y la de Irak en 2003 por parte de los EE.UU. no serían más que una guerra de agresión astuta- mente cubierta bajo el disfraz de la guerra humanitaria. El objetivo de estas guerras consistiría en la consecución de un proyecto imperialista para alcanzar la hegemonía global (Zolo, 2009, pp. 13-114).

5 Las características de la ciudadanía ecológica y las relaciones entre el miedo y la sostenibilidad se analizan en J. Vives-Rego (2013) y M. Cano y J. Vives-Rego (2013).

6 El miedo ha sido considerado desde siempre un factor bélico crucial. Baste mencionar dos casos históricos. El primero es el de los leones de Marco Aurelio durante sus batallas con los marcomanos (Fritz Mauthner, traducción de 2001, pp.165166). Marco Aurelio envió a sus tropas contra los marcomanos, una de las tribus germanas de la época que vivían en la actual Bohemia (República Checa), que eran célebres por su fuerza corporal. Para animar a sus hombres, Marco Aurelio les dio sus leones y los soldados partieron a la lucha alegres porque sabían que los leones causaban terror además de ser fieras de fuerza invencible. Cuando los marcomanos, que nunca habían ni visto ni oído hablar de leones, vieron que se les echaban encima, preguntaron ¿qué es eso? A lo que el jefe de los marcomanos contestó: "esos son perros romanos". Como los marcomanos estaban acostumbrados a que a los perros molestos se les mataban, se enfrentaron a los canes amarillos romanos con sus mazas y los aporrearon hasta matarlos. Si los marcomanos hubieran conocido a los leones y como es lo habitual les hubiesen tenido miedo, no se hubiesen enfrentado y hubiesen sido derrotados. En este caso el no tener miedo seguramente facilitó la victoria, pero de haberlo tenido, el destino de la batalla podría haber sido diferente. El segundo ejemplo es el de la conquista de América por los soldados españoles montados a caballo. Cuando los nativos americanos vieron por primera vez a los soldados montados a caballo, protegidos con armaduras resplandecientes junto al ruido ensordecedor del trepidar de los hierros, los cascabeles que portaban y los cascos de los équidos, más la terrible eficacia de sus espadas y arcabuces, les inspiraron un miedo y un terror que los derrotaron de manera demoledora (Wanty, 1972).

7 Para detalles sobre la heredabilidad sugerimos consultar las siguientes referencias: Ayala y Kiger (1984), Klug et al. (2006), Griffiths et al. (2008) o Benito y Espino (2012).

8 El 6 agosto de 1945 en Hiroshima y el 9 de agosto del mismo año en Nagasaki fueron el día cero de una nueva era en la historia del hombre (para detalles puede consultarse Neufeld, 1991). A partir de ese día el mundo comprendió que la humanidad era capaz de exterminarse a sí misma (Zentner, 1969). En esa línea y viendo los datos científicos y periodísticos vislumbramos y tememos que el hombre puede exterminarse a sí mismo.

9 Las dificultades políticas para tomar decisiones destinadas a evitar los problemas medioambientales se describen en J. Vives-Rego (2011) y los dilemas medioambientales y retos ecoéticos que pueden dar origen a temores, miedos y conflictividad social se analizan en J. Vives-Rego (2010).

10 En la mitología romana el dios Jano (en latín lanus) tenía dos caras. Cada una miraba hacia un lado de su perfil. Simboliza la dualidad del personaje entre el pasado y el futuro. Se consideraba una suerte de héroe cultural, al que se le atribuyen entre otras cosas la invención del dinero, las leyes y la agricultura. Según los romanos, este dios aseguraba buenos finales. 
Ayala, F. J. y Kiger, J. A. (1984). Modern Genetics ( ${ }^{\text {nd }}$ ed.). Benjamin-Cummings Publishing Co.

Benito, C. y Espino, F. J. (2012). Genética. Conceptos esenciales. Madrid: Médica Panamericana.

Blanchard, D. C. y Blanchard, R. J. (1988). Ethoexperimental approaches to the biology of emotions. Annual Review of Psychology, 39, pp. 43-68. http://dx.doi.org/10.1146/annurev. ps.39.020188.000355

Bolles, R. C. (1970). Species-specific defense reactions and avoidance learning. Psychological Review, 77, pp. 32-48. http://dx.doi.org/10.1037/h0028589

Bourke, J. (2005). Fear: a cultural history. London: Virago Press.

Bracha, H. S. (2006). Human brain evolution and the 'Neuroevolutionarytimedepth principle'. Implications for the reclassification of fear-circuitry-related traits in DSM-V and for studying resilience to warzone-related posttraumatic stress disorder. Progress in Neuro-Psychopharmacology and Biological Psychiatry, 30, pp. 827-853. http://dx.doi. org/10.1016/j.pnpbp.2006.01.008

Bracha, H. S., Yoshioka, D. T., Masukawa, N. K. y Stockman, D. J. J. (2005). Evolution of the human fear-circuitry and acute sociogenic pseudoneurological symptoms: the Neolithic balanced-polymorphism hypothesis. Journal of Affective Disorders, 88, pp. 119-129. http:// dx.doi.org/10.1016/j.jad.2005.05.013

Cano, M. y Vives-Rego, J.(2013). El ciudadano ecológico en los procesos de decisión social de la sostenibilidad: tecnociencia, ecoética y cosmovisión. Sociología y Tecnociencia, 4, pp. 38-57.

Fromm, E. (2005). El miedo a la libertad. Barcelona: Paidós.

Gauthier, D. (1969). The logic of Leviathan. Oxford: Oxford University Press.

Gordon, R. (1987). The structure of the emotion. Cambridge: Cambridge University Press.

Griffiths, A. J. F., Wessier, S. R., Lewontin, R. C. y Carroll, S. B. (2008). Genética (9a ed). Madrid: Mc Graw Hill.
Hansberg, O. (1996). La diversidad de las emociones. México D.F.: Fondo de Cultura Económica.

Hettema, J. M. y Kendler, K. S. (2003). A twin study of the genetics of fear conditioning. Archives of General Psychiatry, 60, pp. 702-708. http://dx.doi. org/10.1001/archpsyc.60.7.702

Innerarity, D., y Solana, J. (2011). La humanidad amenazada: gobernar los riesgos globales. Barcelona: Paidós.

Jonas, H. (2004). El principio de la responsabilidad. Barcelona: Herder Editorial.

Klug, W. S., Cummings, M. R. y Spencer, C. A. (2006). Conceptos de Genética (8a ed.). Madrid: Pearson - Prentice Hall.

Lacleau, E. y Mouffe, C. (1985). Hegemony and socialist strategy: towards a democratic radical democracy politics. London: Verso Books.

LeDoux, J. (1998). Fear and the brain: where have we been, and where are we going? Biological Psychiatry, 44, pp. 1229-1238. http://dx.doi.org/10.1016/ S0006-3223(98)00282-0

Mauthner, F. (2001). Contribuciones a una crítica del lenguaje. Barcelona: Herder.

Mineka, S. (1979).The role of fear in theories of avoidance learning, flooding and extinction. Psychological Bulletin, 86, pp. 985-1010. http://dx.doi. org/10.1037/0033-2909.86.5.985

Mineka, S. y Öhman, A. (2002). Phobias and preparedness: the selective, automatic, and encapsulated nature of fear. Biological Psychiatry, 52, pp. 927937. http://dx.doi.org/10.1016/S00063223(02)01669-4

Mouffe, C. (1993). The return of the political. London: Verso Books.

Mouffe, C. (2000). The democratic paradox. London: Verso Books.

Nesse, R. M. (1990). Evolutionary explanations of emotions. Human Nature, 1, pp. 261-289. http://dx.doi.org/10.1007/ BF02733986

Neufeld, J. (1991). Japan in flames. En: Nalty, B. C. (ed.). War in the Pacific. Pearl Harbor to Tokyo Bay. London, Salamander Books, pp. 268-283.
Olsson, A. y Phelps, E. A. (2007). Social learning of fear. Nature Neuroscience, 10, pp. 1095-1102. http://dx.doi. org/10.1038/nn1968

Panksepp, J. (1998). Affective Neuroscience: the foundation of human and animal emotions. New York: Oxford University Press.

Russell, P.A. (1979). Fear-evoking stimuli. En: Sluckin, W. (ed.). Fear in animals and man. New York: Van Nostrand Reinhold, pp. 85-124.

Sklahr, J. (1989). The liberalism of fear. En: Rosenblum, N. (ed.). Liberalism and the Moral Life. Harvard: Harvard University Press.

Strachan, T., y Read, A. P. (2010). Human molecular genetics ( $4^{\text {th }}$ ed.). New York: Garland Science Publishing.

Van Le, Q., Isbell, L. A., Matsumoto, J., Nguyen, M., Hori, E., Mayor, R. S., Tomaz, C., Than, A. H., Ono, T. y Nishijo, H. (2013). Pulvinar neurons reveal neurobiological evidence of past selection for rapid detection of snakes. Proceedings of the National Academy of Sciences, 110, pp. 19000-19005. http://dx.doi. org/10.1073/pnas.1312648110

Vives-Rego, J. (2010). Los dilemas medioambientales del siglo XXI ante la ecoética. Madrid: Bubok.

Vives-Rego, J. (2011). ¿Suicidio político o suicidio ecológico? Madrid: Fundamentos.

Vives-Rego, J. (2013). El ciudadano ecológico: reflexiones sobre algunos contextos sociales y elementos cosmovisionales. Sociología y Tecnociencia, 3, pp. 83-104.

Wanty. E. (1972). L'art de la guerre. Bruselas: Gerard and Co.

Zentner, J. (1969). Die Kriege der Nachkriegszeit. München: SüdwestVerlag.

Zolo, D. (2009). Terrorismo umanitario. Dalla guerra del Golfo alla strage di Gaza. Reggio Emilia: Diabasis. 